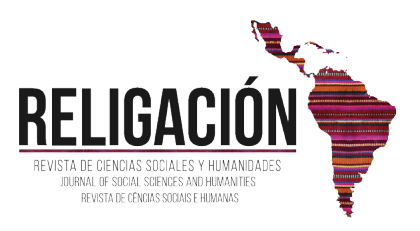

Dossier

\title{
Comentario a los prólogos de "La situación de la clase obrera en Inglaterra", de Friedrich Engels a 200 años de su nacimiento
}

Commentary to the prologues of "The situation of the working class in England", by Friedrich Engels 200 years after his birth

Josemanuel Luna-Nemecio' | Centro Universitario CIFE - MÉXICO |

'Doctor en Geografía por la Universidad Nacional Autónoma de México. Profesor Investigador en el Centro Universitario CIFE (México). Investigador en Ekap University (Estados Unidos). Líneas de investigación: crítica de la economía política con énfasis en estudios territoriales, recursos hídricos, cambio climático y desarrollo social sostenible. email: josemanuelluna@cife.edu.mx

RESUMEN: El estudio ofrece un comentario a los Prólogos de "La situación de la clase obrera en Inglaterra" redactada por Friedich Engels en 1845. El propósito de la presente investigación es conmemorar el bicentenario del nacimiento de Engels, a partir de destacar la vigencia del pensamiento de este revolucionario alemán para pensar la situación de la humanidad proletarizada en el siglo XXI. Los principales resultados fueron: 1) existe una continuidad en el argumento teórico y político desarrollado en el análisis de Engels presentado en los tres Prólogos analizados; 2) para Engels existe una relación entre el desarrollo de capitalismo contemporáneo y las condiciones de posibilidad para la organización política del proletariado; y 3) el pensamiento de Engels es nodal para pensar las condiciones de vida de la humanidad proletarizada en el siglo XXI.

Palabras clave: desarrollo capitalista, Engels, humanidad proletarizada, marxismo, movimiento obrero.

ABSTRACT: The study offers commentary on the Prologues of the book "The situation of the working class in England" written by Friedrich Engels in 1845. The purpose of this research is to commemorate two hundred years of the birth of Engels, considering him as a nodal thinker to think about the situation of the world proletarianized humanity in the 21 st century. The main results were: 1 ) there is a continuity in the theoretical and political argument developed in Engels' analysis presented in the three Prologues analyzed; 2) for Engels there is a relationship between the development of contemporary capitalism and the conditions of possibility for the political organization of the proletariat; 3) Engels' thought is a hub for thinking about the living conditions of proletarianized humanity in the 21 st century.

Key words: capitalist development, Engels, labor movement. proletarianized humanity, Marxism. 


\section{Introducción}

La idea original de este artículo era ofrecer un comentario general a "La situación de la clase obrera en Inglaterra" publicada en 1845 por Friedrich Engels. Sin embargo, dado el espacio reducido con el que se cuenta para este Dossier, el presente estudio se enfoca en hacer comentario sobre los tres Prólogos que enmarcan la exposición general de los once capítulos que - a manera de grandes temasconstituyen los distintos momentos argumentales del libro de Friedrich Engels, "La situación de la clase obrera en Inglaterra"; a partir de este comentario se dicen algunas cuestiones esenciales que rigen para todo el libro. Esta tarea resulta importante en tanto que dicha obra, publicada por primera vez en 1845, guarda una relevancia teórica, histórica y política para pensar la situación de la humanidad proletarizada en el siglo XXI; sobre todo, ahora que el propio desarrollo histórico del capitalismo ha producido una crisis civilizatoria de dimensiones geopolíticas que corresponden con la medida territorial del mercado mundial realizado. Aunque el estudio de Engels puede ser interpretado uno un análisis descriptivo sobre las condiciones mentales, físicas y psicologías que caracterizan la vida cotidiana de la clase trabajadora inglesa, en realidad, el texto presenta un planteamiento de mayor alcance teórico y político dadas las conclusiones revolucionarias y militantes a las que arriba (Dennehy, 1996)

Para ofrecer una argumentación sobre dicha afirmación, es importante comenzar por establecer algunas ideas acerca del contexto histórico en el que fue escrito este libro. Recordemos que la primera visita de Friedrich Engels a Inglaterra fue entre noviembre de 1842 y agosto de 1844 (Roggerone, 2013); tras ser enviado allí por su padre para separarle del ambiente revolucionario que se vivía en Berlin (Kohan, 2007); dicha estancia propició un momento decisivo para desarrollar su posicionamiento de clase en favor del proletariado (Grüner, 2006). La realidad de la vida cotidiana de la clase obrera inglesa impresionó a Engels en tal medida que lo hizo convencerse de defenderle y luchar por su liberación.

Engels trabajó en la fábrica inglesa donde su padre era accionista: la empresa "Ermen \& Engels"; ello le posibilitó entrar en contacto directo con el proletariado, permitiéndole contar con la oportunidad de recorrer los barrios obreros y testificar los sufrimientos y miserias en los que vivía el proletariado inglés (Lenin, 1895). El trabajo de investigación desarrollado por Engels tiene el propósito de retratar las abrumadoras condiciones de vida de la clase proletaria en las ciudades de Manchester y Liverpool (Asiner, 2018), en tanto que en dichas urbes se concentraba el núcleo industrial de Inglaterra hacia fines de la primera mitad del siglo XIX. Estos espacios urbanos sirvieron como un campo de observación para dar cuenta del deterioro de las condiciones de vida de la clase proletaria, conforme el modo de producción capitalista se iba desarrollando en Europa; permitiéndole a Engels observar de primera mano y por medio de fuentes documentales publicadas en los llamados "Libros Azules" y otros documentos oficiales, la afectación sobre la salud y calidad de vida del proletariado que generaba la subsunción formal y real del proceso de trabajo inmediato bajo el capital (Marx, 1987).

Hacia mediados de la década de los cuarenta del siglo XIX, la medida geopolítica de capital que mostraba el grado de desarrollo del capitalismo era de dimensiones meramente continentales (Veraza, 2013). Europa era, precisamente, el territorio en el cual los mecanismos de extracción de plusvalor absoluto y relativo a la clase obrera se encontraban desarrollándose en su especificidad capitalista. El desarrollo del modo histórico de producción capitalista sobre el territorio europeo, produjo las condiciones para la extracción de plusvalor a la clase proletaria por la burguesía de países como Alemania, Francia y, principalmente, Inglaterra (Hobsbawm, 1977). Esta explotación de plusvalor por el capital industrial se llevaba a costa de producir sufrimiento, hambre, enfermedades y muertes en las miembros de la clase proletaria; paralelamente, se generaba un impacto negativo sobre las condiciones biofísicas del territorio, pues las empresas capitalistas las contaminaban y sobreexplotaban para intentar satisfacer -inmersas en una lógica crematística de producción (Marx, 1975) - su hambre de plusvalor como parte de la reconfiguración urbana de la sociedad agraria europea de mediados del siglo XIX.

El análisis presentando por Engels en las páginas de la Situación de la clase obrera en Inglaterra resulta sumamente importante para poder llevar a cabo un desarrollo de la propia Crítica de la Economía Política cuyo plan de general de seis libros (Moreno \& Pereira, 2018) tenía como principal objetivo llevar a cabo una crítica global a la sociedad burguesa. Al respecto hay que precisar que de los seis libros planeados (El capital, La renta de la tierra, Trabajo asalariado; Comercio internacional y Mercado Mundial), Marx y Engels solamente alcanzaron a darle una figura redonda y completa al primero de ellos; quedando, precisamente, en El capital. Crítica de la Economía Política (Marx, 1975) apenas si esbozados algunos argumentos y tesis que son decisivos a retomarse para realizar la crítica de la totalidad de las relaciones sociales y de producción y de las fuerzas productivas en el capitalismo. 
Así, dentro de la crítica de la economía política comenzada por Engels en 1843 con su Esbozo de la crítica de la economía política (Santella, 2018), y el trabajo de Marx de continuar, desarrollar, perfeccionar y potencializarla hasta su figura completa, "La situación de la clase obrera en Inglaterra" (Engels, 1976) resulta en ser estratégica para comprender el grado de concreción que debería tener la crítica a la sociedad capitalista en lo que respecta a las condiciones de posibilidad necesarias para la reproducción de la fuerza de trabajo en el capitalismo.

Es de reconocerse que el análisis presentado por Engels en "La situación de la clase obrera en Inglaterra", fue altamente clarificador para el análisis crítico revolucionario presente en el pensamiento de Karl Marx, quien quedó altamente impresionado por la exposición realizada por Engels acerca de las condiciones de vida del proletariado inglés (Asiner, 1976), además que, posteriormente, el revolucionario de Tréveris reconociera que Engels llegase a los mismos resultados que él (Marx, 1990), acerca de los efectos generados por el capitalismo sobre la clase trabajadora (Dannehy, 2005). Además, Marx utilizó parte del análisis presentado por Engels en "La situación de la clase obrera en Inglaterra" para ilustrar algunos de sus argumentos desarrollados en El capital (Marx, 1975); por sólo mencionar un ejemplo, en el capítulo XIII del tomo I, dedicado al tratamiento de la Maquinaria y Gran Industria, Marx refiere el libro de Engels para argumentar la degradación intelectual que, artificialmente, sufren los obreros al ser convertidos a simples máquinas destinadas a la generación de plusvalor.

El reconocimiento del libro de "La situación de la clase obrera en Inglaterra" no fue exclusivo de Marx sino, también, fue de alta estima por otra serie de pensadores afines al marxismo y a la lucha de los dominados modernos por liberarse; estos pensadores veían en "La situación de la clase obrera en Inglaterra", una radiografía de cómo el modo de producción capitalista explota a la humanidad. Por ejemplo, Paterson (2014) la considera como la primera antropología empírica de una comunidad urbana en tanto que es Engels quien, por medio de la intervención de la combativa obrera irlandesa Mary Burns (Kohan, 2007), comenzara a recolectar información de primera mano de las condiciones de vida de las familias y barrios ingleses para realizar su estudio etnográfico, mientras compartía los alimentos y participaba en reuniones de índole política en los círculos obreros (Kohan, 2007).

Vladimir I. Lenin fue otro pensador y político que tomó en alta consideración "La situación de la clase obrera en Inglaterra". Para el revolucionario ruso, Friedrich Engels representaba el científico más descollante y un maestro para el proletariado; su libro, según Lenin, representaba un escrito cautivador que exponía una descripción fidedigna de la forma patética en la que vivía el proletariado inglés. Lenin consideraba que dicho libro significaba una denuncia de las penurias que la burguesía generaba sobre la vida del proletariado. Según Lenin, el impacto que tuvo el libro de "La situación de la clase obrera en Inglaterra" en los movimientos revolucionarios del proletariado europeo y ruso fue grande, pues era reconocido como la mejor, más veraz y brillante radiografía de la situación de la clase obrera que hasta ese momento se había escrito (Lenin, 1895).

Para Franz Fanon, "La situación de la clase obrera en Inglaterra" guardaba un lugar muy importante en tanto que le sirvió como fundamento e influencia para la elaboración de su libro Los condenados de la Tierra. Es importante recordar que Fanon es considerado como uno de los críticos más importantes y reconocidos al racismo colonial en relación al capitalismo. En su obra, el teórico nacido en Martinica, plantea que la desigualdad y opresión producidas por la burguesía en el capitalismo, se ha traducido en un racismo generalizado; de allí que Fanon fuese considerado como un defensor activo de los pueblos oprimidos colonizados y un acérrimo crítico de aquellos quienes promovían dichas relaciones de explotación (Valero, 2010).

Para que Fanon elaborara sus brillantes aportes críticos a la colonización, fueron fundamentales los argumentos presentados por Engels en "La situación de la clase obrera en Inglaterra"; en particular, el apartado referente a "La inmigración irlandesa" en donde se explican las causas y extensión de la migración en referencia a las condiciones de desaseo, rudeza y alcoholismo que caracterizaba la situación de vida de los migrantes irlandeses en los barrios más degradados del Inglaterra (por ejemplo "Little Ireland" [La pequeña Irlanda], así como el efecto que, en términos de competencia y de presión a la baja del salario del proletariado inglés, representa la fuerza de trabajo irlandesa.

En relación al reconocimiento implícito que Franz Fanon hace a Friedrich Engels, es importante recordar el prefacio que Jean Paul Sartre redactó para la primera edición de Los condenados de la Tierra, en el cual — de forma explícita- se establece una relación entre el autor de "La situación de la clase obrera en Inglaterra" y el del libro Piel negra, máscaras blancas (Fanon, 2009). Tanto Engels como 
Fanon —diría Sartre— se dan a la tarea de poner sobre la mesa la relación que existe entre capitalismo, colonialismo y el mercado mundial (Valero, 2010).

Una valoración adicional a los recién mencionados en referencia a "La situación de la clase obrera en Inglaterra" es el realizado, desde la sociología y el urbanismo, por Henri Lefebvre, para quien el libro de Engels resultara estratégico para su estudio sobre el espacio (Lefebvre, 1991) y lo urbano (Lefebvre, 2003), Es importante reconocer que en 1976, Lefebvre profundiza en el estudio de Engels para redactar su libro El pensamiento marxista y la ciudad, prestando principal atención al problema de la producción y reproducción de condiciones de alta desigualdad al interior del espacio urbano (Scarpacci, 2016).

Aunado a los reconocimientos de estos teóricos afines a la causa política del proletariado moderno, es importante considerar que "La situación de la clase obrera en Inglaterra" de Friedrich Engels representa una importante radiografía de los efectos que la subsunción formal y real del proceso de trabajo inmediato por el capital genera sobre las condiciones materiales de vida de la humanidad. La exposición de Engels ofrece una crítica radical sobre la reconfiguración urbana y degradante de la vida del proletariado en las ciudades, las enfermedades y vicios que forman parte de la cotidianidad degradada en que se vive, la falta de educación, la pobreza, las perturbaciones sexuales, los crímenes, la negligencia moral y la guerra social que emana de una reproducción social subordinada a la acumulación creciente de capital. "La situación de la clase obrera en Inglaterra" se posiciona como una de las obras más importantes y estratégicas que - junto con El capital. Crítica de la Economía Política de Marx- sirven como una referencia para comprender la situación de explotación que vive la humanidad proletarizada en pleno siglo XXI y las condiciones de posibilidad para superarle mediante una revolución proletaria de carácter internacional.

El libro de "La situación de la clase obrera en Inglaterra" de Engels redactada hacia fines de la primera mitad del siglo XIX, es más que pertinente para poder pensar nuestro tiempo y la situación de la humanidad proletarizada. Sin embargo, hay que reconocer el grado de desarrollo y perfeccionamiento que actualmente han tenido los mecanismos de extracción de plusvalor absoluto y relativo a la clase obrera por parte del capitalismo, así como dar cuenta que el tipo de desarrollo que han tenido las fuerzas productivas del capital, hoy día tiene la principal característica de estar nucleado por una tecnología capitalista específicamente nociva que les hace devenir en fuerzas destructivas orientadas a la producción de valores de uso cuya génesis y estructura es de alta nocividad (Veraza, 2011).

En el siglo XXI la subsunción real del proceso de trabajo por el capital se ha complicado hasta devenir en una subsunción real del consumo por el capital (Veraza, 2009), por lo que los efectos degradantes de las condiciones de vida y de reproducción de la fuerza de trabajo proletaria se ha también complicado. Es así que, para enfatizar en la vigencia que tiene el libro de "La situación de la clase obrera en Inglaterra" y como una forma de homenajear a Friedrich Engels a 200 años de su nacimiento, el presente estudio se propone como meta el presentar un comentario sobre los Prólogos que Engels redactara para la edición inglesa, norteamericana y alemana de su libro, con la finalidad de comprender el sentido que su propio autor le encontraba a su obra en relación a la lucha del proletariado en contra de la clase burguesa. Además, se ofrecerán las líneas generales que pudiesen llegar a contener los argumentos que, posiblemente, serían desarrollados hoy día por Engels para pensar la lucha de clases y la situación del proletariado mundial en el siglo XXI.

\section{Acerca de los prólogos}

El contenido del libro de "La situación de la clase obrera en Inglaterra" cuenta con tres Prólogos redactados por Engels en los cuales podemos encontrar argumentos sumamente importantes que van más allá de una simple presentación o introducción a la temática general de la obra. En 1845 Engels redacta el primer Prólogo a su libro durante su estancia en Bremen con fecha del 15 de marzo; en el cual, según abordaremos más adelante, se va a abordar lo específico de la estructura de la lucha de clases desde la perspectiva de la crítica de la economía política y el materialismo histórico.

El segundo Prólogo fue redactado el 26 de enero de 1887 — cuatro años después de la muerte de Marx - para la edición norteamericana de "La situación de la clase obrera en Inglaterra", mientras Engels se encontraba en Londres. En los párrafos que le constituyen se puede reconocer un importante análisis político revolucionario de la lucha de clases desarrollada en Europa y contrastándole con la formación 
de la clase obrera en Estados Unidos. En dicho prologo Engels presenta un análisis sobre el movimiento de organización política del proletario en la nación norteamericana como expresión de las crecientes contradicciones que iba mostrando el desarrollo de la medida geopolítica de capital intercontinental y la correlativa subordinación formal y real del proceso de trabajo por el capital en Estados Unidos.

Durante el año de 1892, a tres años antes de morir, Engels redacta un tercer prólogo a "La situación de la clase obrera en Inglaterra", el cual enmarca la edición alemana de su libro. En él podemos reconocer no sólo una mayor agudeza en la mirada crítica de Engels, sino que, también, una clara continuidad y coherencia teórica y política en el pensamiento de Engels en relación a los ideales de la revolución comunista. Además, se presenta una interesante lectura materialista del desarrollo del mercado mundial capitalista, en la que Engels muestra que, a la luz de los años del desarrollo del capitalismo en Europa, éste se va consolidando como un modo de producción potente y de alta capacidad adaptativa para asegurar su desarrollo histórico.

Aunque cada uno de los tres Prólogos que enmarcan el contenido argumental de "La situación de la clase obrera en Inglaterra" tienen una especificidad histórica, geográfica y temporal a partir del lugar y fecha en que fueron redactados por Engels, guardan una doble conexión que les relaciona. En primer lugar, van dirigidas a la naciente clase proletaria que día a día ven mermadas sus condiciones de reproducción, teniendo que sobrevivir en medio de una normalidad degrada y degradante; es decir, Engels le habla directamente al proletariado como sujeto histórico en potencia. En segundo lugar, en los Prólogos de su libro, Engels muestra el potencial científico de la para entonces embrionaria crítica de la economía política y del materialismo histórico para denunciar la serie de vejaciones que el modo de producción capitalista comete en contra de las condiciones de vida para la reproducción de la fuerza de trabajo obrera en la sociedad burguesa.

Aunque Engels redacta los Prólogos de "La situación de la clase obrera en Inglaterra" para la clase obrera inglesa, norteamericana y alemana, sus argumentos terminan por tener eco en la humanidad proletarizada conforme el modo de producción capitalista pasa de ser internacional a ser mundial y, por lo tanto, se generan las mismas condiciones de miseria que correspondientemente se produjesen en Europa; demostrándose, precisamente, que aquella advertencia realizada por Marx en el Prólogo a la primera edición de El capital —veintidós años antes de ser redactada por el revolucionario de Tréverisya era señalada en "La situación de la clase obrera en Inglaterra". Cuando Engels presenta que la situación del proletariado inglés muestra el posible decurso histórico de las condiciones de vida del proletariado europeo y norteamericano -y ahora en 2020 podemos decir mundial-, está diciendo indirectamente "De te fabula narratur" (Marx, 1975:8) o, bien, "a ti se refiere la historia", como una forma de advertirle al proletariado el futuro decadente que el capitalismo le depara.

Pero los Prólogos no sólo tienen ese talante de advertencia o señalamiento de las consecuencias que representa la concreción del desarrollo capitalista para las condiciones de vida del proletariado. Sino que, también, a la hora de reconstruir el proceso de organización y movilización del proletariado para luchar por mejores condiciones de vida, los argumentos allí vertidos por Engels permiten dar cierto principio esperanzador y de urgencia para la lucha en contra del capital. Es decir, que "La situación de la clase obrera en Inglaterra" es ante todo un instrumento de formación política del proletariado como fuerza antagónica de la burguesía. Además, se puede observar cómo — con cada uno de los PrólogosEngels busca poner al día su libro en referencia al desarrollo histórico del capitalismo y a la serie de temas que Marx tratase en El capital, en referencia al plusvalor, la reproducción simple y ampliada de capital y la caída tendencial de la tasa de ganancia a decrecer.

\section{La relación entre el estudio de la situación de la clase trabajadora en el capitalismo inglés y la lucha de los movimientos obreros: argumento central del prólogo a la edición inglesa de 1845.}

En la redacción del primer Prólogo a la edición inglesa de "La situación de la clase obrera en Inglaterra", se pueden reconocer argumentos importantes de índole metodológica y epistemológica que, si bien sirven para contextualizar y explicar la investigación desarrollada por Engels en su libro, también permiten entrever el sentido que tiene la crítica de la economía política y el materialismo histórico en la perspectiva teórico y practico política de Friedrich Engels para llevar a cabo la denuncia de la destrucción de la vida cotidiana por parte del capitalismo. 
En el primer párrafo del Prologo escrito por Engels en 1845, se puede advertir que "La situación de la clase obrera en Inglaterra" resultó por ser un libro sobre las condiciones de vida de la clase proletaria en el capitalismo, cuya extensión temática y argumental sobrepasó, incluso, las intenciones primigenias del propio Engels, quien pretendía que su estudio fuera presentado "simplemente en forma de capítulo" en lo que sería el proyecto de realizar un tratamiento monográfico sobre "la historia social de Inglaterra" (Engels, 1976: 5).

La relevancia del contenido argumental de "La situación de la clase obrera en Inglaterra" no sólo consiste en retratar las condiciones de miseria en las que tiene que vivir el proletariado inglés, sino que, también, permite reconocer la relación entre la situación de la clase asalariada y la emergencia de movimientos obreros que buscaran mejorar la vida del proletariado y que enarbolaban la bandera del comunismo tanto en Francia como en Alemania. Para Engels resulta estratégico que se de cuenta de las condiciones de vida del proletariado, pues esto es un elemento indispensable para el desarrollo y especificidad de las teorías socialistas (Engels, 1976) y, por lo tanto, el evidenciar cómo es que (sobre) viven los trabajadores en el capitalismo, se vuelve necesario y estratégico para una revolución de corte proletario; podemos reconocer, entonces, que para Engels la práctica revolucionaria presente en la organización y movilización europea, es indispensable para el desarrollo de una teoría que piense la transformación social y viceversa.

Engels justifica que su estudio sobre las condiciones de vida de la clase trabajadora haya tenido lugar en la Inglaterra del siglo XIX, pues es, precisamente, en dicho territorio, que el proletariado existía "en su forma clásica", además que en Inglaterra se encontraban "reunidos los materiales necesarios" para completar el análisis sobre la reproducción de la fuerza de trabajo proletaria en el capitalismo. En este sentido, el trabajo de Engels se posiciona como original y único en su tiempo, no sólo por la metodología de investigación que busca obtener información de primera mano sobre las condiciones de la vida cotidiana de la clase trabajadora, sino que, también, porque todo lo que es mencionado por Engels, es por él comprobado y argumentado hasta sus últimas consecuencias, lo cual vuelve muy complicado que le sea impugnada alguna inexactitud o mentira en sus planteamientos.

La expansión geopolítica del mercado mundial capitalista tiene como correlato el internacionalismo proletario; esto es argumentado por Engels en el primer Prologo de "La situación de la clase obrera en Inglaterra" bajo una conexión condicionante, en la que se enfatiza que, ante el desarrollo del capitalismo en Europa, la situación de miseria que vive el proletariado inglés debe ser de interés por toda la clase trabajadora europea en tanto que es un escenario en el que, más temprano que tarde, se encontrará toda la masa de obreros que el capital despoja de los medios sociales de producción para subordinarles bajo la égida de la valorización del valor.

Engels advierte que dicha relación entre la subordinación de la vida cotidiana por el capital como consecuencia del desarrollo del complejo maquinístico gran industrial, la correspondiente explotación de plusvalor y la configuración de espacios de resistencia y lucha obrera -así como la comprensión de la vida cotidiana del proletariado_ no había sido abordada en su especificidad por los teóricos en Europa, principalmente los alemanes. Además, la crítica de Engels hacia la falta de estudios sobre los efectos que el desarrollo del capitalismo produce sobre las condiciones de vida de la clase proletaria, enfatiza en el hecho que, para mediados del siglo XIX, no existían investigaciones que aludieran a las condiciones de posibilidad necesarias para la superación de la explotación de la que era objeto el proletariado.

Friedrich Engels termina la redacción de este Prólogo a La situación de la clase obrera con dos observaciones. La primera, referente al uso que a lo largo del texto hace del término clase media (middle class), la cual, en términos específicos, no es otra más que la burguesía; esta variante entre la palabra inglesa y la francesa, permite caracterizar a quiénes detentan la propiedad privada de los medios sociales de producción tanto económicos como políticos en el capitalismo. En este mismo sentido, Engels especifica el concepto de proletariado al enmarcar en éste a los obreros, clase obrera e, incluso, a la propia clase indigente; pues estos términos eran parte del lenguaje empleado por las investigaciones inglesas para aludir a los dominados modernos, queriéndola mostrar como un disgregado heterogéneo de diversos actores diferenciados, llegando incluso a reconocer la existencia de condiciones de vida miserables solamente en espacios rurales, poniendo como polo opuesto y de máximo desarrollo a las ciudades.

En síntesis, en el primer Prólogo de "La situación de la clase obrera en Inglaterra", podemos reconocer la práctica metodológica de Engels para realizar su investigación, misma que no sólo es 
la exposición de tal o cual proceder para recabar, organizar o criticar información empírica o datos estadísticos, sino que, también, muestra un claro posicionamiento de clase por parte del autor, además de mostrar la originalidad de la obra respecto al tratamiento que dicha temática había tenido hasta el momento. Esta tarea pedagógica por parte de Engels de explicar cómo y en qué sentido se hizo la investigación de su libro, guarda una importancia teórica y política fundamentales, pues se enfatiza en la necesidad de tener rigurosidad conceptual al llamar por su nombre a los representantes de la lucha de clases (burgueses y proletario) que se enfrentan cotidianamente, unos para salvaguardar las condiciones que les aseguren seguir detentando la propiedad privada de los medios sociales de producción y, otros, que tienen que defenderse y asegurar contar con las condiciones mínimas para su reproducción vital, incluso si esto representa organizar y luchar en contra de sus opresores.

Además, en este primer Prólogo, según vimos, se puede encontrar que para Engels resulta muy importante la relación entre la práctica política y el desarrollo de una teoría que permita pensar en estrategias y caminos para transformar las condiciones de miseria en las que el capitalismo ha sumido al proletariado; por lo que la denuncia de cada una de las vejaciones que la burguesía comete en contra de las condiciones de posibilidad para la reproducción de la fuerza de trabajo proletaria, es también una guía política de la agenda de lucha de los movimientos obreros.

\section{El desarrollo del capitalismo norteamericano y el análisis político revolucionario de la lucha de clases en el Prólogo a la edición norteamericana de 1887.}

El Prólogo que Engels presenta para la edición norteamericana de "La situación de la clase obrera en Inglaterra", se ve complementado con el "Fragmento del apéndice de Engels" a esa misma edición redactado en 1886, es decir, un año antes de que el libro en cuestión fuera publicado en Estados Unidos. En dicho Apéndice, se encuentra un importante análisis del desarrollo del capitalismo en el continente americano, precisamente, en la nación que a la mitad del siglo XX se convertiría en la que hegemonizaría el decurso histórico del modo de producción específicamente capitalista (Veraza, 2004) y que el propio Engels anuncia como una nación que lucha tenazmente por ser la vanguardia en el proceso de industrialización (Engels, 1976: 8). Sorprende entonces la agudeza y tino del pronóstico histórico que, desde una perspectiva materialista, Engels vaticina casi sesenta años antes de que ocurriera la hegemonía mundial del capitalismo por Estados Unidos.

La descripción hecha por Engels sobre el proceso de desarrollo del capitalismo en Estados Unidos comienza por la exposición de la acumulación originaria de capital en el territorio norteamericano, la cual no sólo produjo la concentración de los medios sociales de producción en manos de la burguesía, sino que, también, produjo una masa de proletarios que terminarían por verse en condiciones de reproducción similares a las expuestas por Engels para el caso de la clase trabajadora inglesa.

Esta historia del desarrollo del capitalismo en Estados Unidos y la correlativa configuración de la lucha de clases en dicho territorio, es complementado por los argumentos que Engels presenta en el Prólogo a la edición norteamericana de 1887 y que se titula "El movimiento obrero en América (EE. UU.)", en el cual podemos observar una continuidad con el argumento redactado en 1845 cuando Engels recalcaba la importancia de no sólo hablar de las condiciones de vida del proletariado en el contexto de los abusos y violencias perpetuados por el capitalismo sino que, también, se tenía que mostrar cómo la existencia de éstas se tornaban en condición de posibilidad para la emergencia de un movimiento proletario que, ya en la práctica - y como expresión del propio desarrollo de una medida geopolítica intercontinental del capital (Veraza, 2013)_, demostraba la importancia de que fuera, precisamente, internacional.

El caso de la organización obrera en Estados Unidos sorprende por lo rápido que se configurase, pues mientras en otros países hubiese tardado diez años en producirse, en Norteamérica se desarrolló en sólo diez meses (Engels, 1976). Hasta inicios 1885, el surgimiento de la clase proletaria y la correlativa lucha de clases parecía un fenómeno social exclusivamente europeo; sin embargo, Engels comenta que a partir de acontecimientos como la huelga de los Mineros en Pennsylvania se posibilitó que, para mayo de dicho año, el movimiento obrero se propagase como "incendio en la pradera" (Engels, 1976:10).

El desarrollo de las contradicciones que trajo consigo el propio proceso de subsunción formal y real del proceso de trabajo por el capital en Estados Unidos, hizo que más temprano que tarde "los 
movimientos espontáneos e instintivos" de la clase obrera norteamericana comenzaran a converger en una lucha común y simultánea "contra una miserable situación social" (Engels, 1976: 10) a la que era orillada para sobrevivir, como efecto de una misma causa, a saber: el desarrollo de capitalismo como modo de producción específico en Estados Unidos. Es así que, este Prólogo a la edición norteamericana de "La situación de la clase obrera en Inglaterra", permite reconocer que con el desarrollo del capitalismo y la escisión de la sociedad en clases antagónicas, se produce, precisamente, a quiénes serán los propios sepultureros de dicho modo de producción.

La velocidad con la que, según la descripción de Engels (1976), se llevó a cabo la organización del proletariado en Estados Unidos, pasa por la configuración de una consciencia de clase (Luckács, 1975) de tipo proletaria, a partir de la cual los obreros dejarían de reconocerse como individuos heterogéneamente diferenciados para comenzar a auto percibirse como miembros de una misma clase económica y, por lo tanto, como integrantes de una fuerza política que representaría de suyo un intento de contrarrestar el propio desarrollo del capitalismo.

Al respecto, cabe reconocer que esta especificidad de la lucha de clases en Estados Unidos, es explicada por Engels por las propias condiciones histórico-objetivas con las que el capitalismo se encontrase en Estados Unidos para lograr romper los limites geopolíticos de su medida continental y avanzar hacia la subordinación del proceso de trabajo en Norteamérica; es decir, que si bien el movimiento proletario pudo desarrollarse y articularse en un sorprendente periodo de sólo diez meses, se debe a que el desarrollo del capitalismo en dicha nación, se llevó a cabo sin las contradicciones que, por ejemplo, en Europa representó la coexistencia contradictoria entre el modo de producción capitalista y el feudal.

Pero más allá de las diferencias temporales, territoriales e, incluso, histórico concretas que presenta el desarrollo del capitalismo en Estados Unidos respecto a Europa, Engels insiste en reconocer que, al final, se ha arribado al mismo destino: una degradación de las condiciones de vida del proletariado como resultado del desarrollo de la subordinación formal y real del proceso de trabajo por el capital; por lo que ante un enemigo común, el tema del internacionalismo de la lucha proletaria es enfatizado como parte de la búsqueda de un "remedio común para estos padecimientos comunes", mismo que, insiste Engels, debe formar parte de un partido político de base proletaria, tal y como quedó asentado en el Manifiesto del Partido Comunista publicado en 1848 (Marx \& Engels, 1974). Esta conformación de una directriz política que enfatice la necesidad de luchar contra el capitalismo donde quiere que éste se encuentre, lleva consigo la advertencia de Engels de no tener como finalidad última la toma del poder, sino que, en todo caso, ésta es vista como una condición sine qua non para poder liberar a la humanidad de las cadenas que hasta el momento han caracterizado la prehistoria humana.

Tras la presentación de las condiciones y especificidad de la expropiación de los medios de producción y la correlativa explotación de la fuerza de trabajo proletaria en el capitalismo, diferenciándole de la esclava y feudal, Engels argumenta en el Prólogo a la edición norteamericana de "La situación de la clase obrera en Inglaterra", que la subordinación de la fuerza de trabajo proletaria al capital no está sola y exclusivamente en la tenencia de la tierra, sino en la propiedad privada que la burguesía ha hecho de todos y cada uno de los medios sociales de producción; este planteamiento permite reconocer los límites de ciertas vetas políticas —como la del socialista Henry George (Engels, 1976: 15)_ que al enfocar su crítica al capitalismo en el tema de la propiedad de la tierra, no cuestionan el fundamento del modo de producción específicamente capitalista, a saber: la explotación de plusvalor al interior del proceso de producción.

El camino argumental desarrollado por Engels en el Prólogo a la edición norteamericana de "La situación de la clase obrera en Inglaterra", pasa por revisar las principales corrientes políticas en las que convergiera el proletariado norteamericano para llevar a cabo una lucha y resistencia en contra de la clase burguesa en Estados Unidos. Se presenta la historia de configuración de "Los Caballeros del Trabajo", la cual es "la primera organización nacional creada por el conjunto de la clase obrera norteamericana (Engels, 1976: 16), representando un principio de esperanza para la lucha proletaria en Estados Unidos durante el año de 1887, al lograrse adaptar a las necesidades concretas de la lucha de clases en suelo norteamericana. En este mismo sentido, se aborda al Partido Socialista del Trabajo, el cual fue organizado por migrantes alemanes que mantenían fuertemente sus raíces culturales e ideológicas, así como toda la experiencia acumulada por la lucha proletaria en Europa; siendo una gran oportunidad para el proletariado norteamericano contar con más de cuarenta años de lucha sintetizadas en el programa de acción política del Partido Socialista del Trabajo (Engels, 1976); de allí que, esta fuerza política, fue considerada en alta estima por Engels, no sin antes advertir la ineludible necesidad de "despojarse de todo vestigio de su indumentaria extranjera" (17) y, por lo tanto, "llegar a ser norteamericano hasta la médula" (17). 
La historia de la configuración de diversos frentes de resistencia y lucha de la clase obrera norteamericana para organizarse en una misma dirección, más allá de sus especificidades y contradicciones, muestran una realidad innegable: la necesidad de unificar en una sola fuerza política, en un gran y único "ejército nacional del trabajo con un programa común" (Engels 1976: 18). La superación de las limitantes y contradicciones de la propia organización proletaria en Estados Unidos se posibilita, según lo expuesto por Engels hacia el final del Prólogo a la edición norteamericana de "La situación de la clase obrera en Inglaterra", con la adopción de una agenda política cuya acción esté basada en lo expuesto en el Manifiesto del Partido Comunista (Marx \& Engels, 1974). Así, los triunfos que la gesta proletaria auspiciados por la bandera comunista tuviesen en Alemania, Francia, Bélgica, Holanda, Suiza, Dinamarca, Suecia, España y Portugal, son presentados por Engels a una masa de trabajadores norteamericanos que han visto mermadas sus condiciones de vida por el desarrollo propio del capitalismo en Estados Unidos.

Engels hace un trabajo de organización del trabajo obrero de tipo internacionalista partir de la publicación de "La situación de la clase obrera en Inglaterra" y, en particular, en el Prólogo a la edición norteamericana de dicho libro. Esta argumentación es importante, en tanto que para 1887 en que el Prólogo es redactado, se encuentra a dos años antes de que se organizara la Segunda Internacional, (1889), la cual, desafortunadamente, no retomó la propuesta de Engels de que el movimiento internacional del proletariado se condujese de acuerdo a los planteamientos políticos plasmados en el Manifiesto del Partido Comunista (Marx \& Engels, 1974).

En síntesis, en el Prólogo a la edición norteamericana de "La situación de la clase obrera en Inglaterra", se pueden encontrar argumentos que se dirigen hacia la necesidad de reconocer un común denominador en la historia del proletariado tanto europeo como americano, a saber: la degradación de las condiciones de vida de la fuerza de trabajo obrera conforme el capitalismo se va consolidando como modo de producción hegemónico. Además, se advierte la necesidad de luchar en un frente común, precisamente, en contra de las vejaciones que la burguesía lleva a cabo en contra de la clase trabajadora; para lo cual es de suma importancia reconocer la especificidad de la explotación en el capitalismo, más allá del simple despojo de tierras que caracterizan el proceso de acumulación originaria de capital pero que no es sino condición para el desarrollo de los mecanismos de explotación de plusvalor absoluto y relativo a la clase obrera; reconociéndose, precisamente, como una clase que emerge y se desarrolla como expresión directa de un mismo proceso que acontece ya intercontinentalmente, la necesidad de impulsar un internacionalismo proletario es una tarea a desarrollar a partir de reconocer los logros que el propio movimiento proletario había tenido en Europa mediante la acción política de los comunistas.

\section{La perspectiva del desarrollo del capitalismo en el Prólogo a la edición alemana de $\mathbf{1 8 9 2}$}

En el primer párrafo del Prólogo a la edición alemana escrito por Engels en 1892, podemos encontrar una continuidad en la perspectiva crítica, histórica y político revolucionaria del autor de "La situación de la clase obrera en Inglaterra"; pero dicha congruencia entre lo escrito por Engels en 1845 y lo redactado cuarenta y siete años después, no aparece inalterada sino que el propio desarrollo intelectual y político de Engels, así como el propio decurso del desarrollo histórico del capitalismo, le permitió tener al autor una mayor agudeza en su mirada crítica. Esto se puede constatar en la serie de correcciones a los párrafos y notas añadidas bajo la forma de pie de página que fueron escritas en 1892, precisamente, para la publicación del libro en Alemania.

La idea de la homologación de las condiciones económicas y el correlativo estado de degradación de la vida del proletariado que el capitalismo produce mientras se desarrolla en el mundo, aparece nuevamente como línea base del argumento que Engels expone, ahora, para la presentación al público alemán —tal y como lo hiciera previamente para el inglés y el norteamericano- de "La situación de la clase obrera en Inglaterra". En el Prólogo escrito para la edición alemana de dicho libro, podemos encontrar un análisis general — pero no por ello menos preciso- de las tendencias que Engels observa respecto al desarrollo de la medida geopolítica del capitalismo (Veraza, 2013) hacia fines del siglo XIX.

Mencionando la capacidad adaptativa y de perfeccionamiento que el capital despliega para mejorar y sofisticar sus mecanismos de explotación conforme se desarrolla, Engels muestra una lectura histórico materialista sobre el desarrollo internacional del capitalismo, sobre todo, mediante la 
construcción de medios de comunicación basados en ferrocarriles y trasatlánticos que sirvieron como fuerzas productivas para la acumulación de capital, siendo la antesala de la posterior realización del mercado mundial. A la luz de los años, el desarrollo del capitalismo y las contradicciones económicas y políticas que a partir de éste se desplegaron en Inglaterra y toda Europa, resultaron mínimas respecto a las trasformaciones que el capital producía en América; demostrando que, conforme se desarrolla, el modo de producción específicamente capitalista se supera a sí mismo.

El Prólogo a la edición alemana de 1892 de "La situación de la clase obrera en Inglaterra", permite reconocer que, para Engels, la serie de deficiencias y penurias que vive el proletariado a raíz del desarrollo histórico del capitalismo, tienen que ser explicadas más allá de una simple "deficiencia aislada" (Engels, 1976: 29) , sino que deben partir de criticar la estructura del propio capitalismo, enfatizando la relación de explotación que el burgués entabla con el proletariado a cambio de "un jornal" que no cubre la totalidad del tiempo de trabajo que dura la jornada laboral y que representa un valor extra al invertido por el capitalista y que es producido, precisamente, mediante el plustrabajo que el obrero entrega al burgués para que éste se embolse el plusvalor generado; encontrándonos aquí con que este argumento de Engels pasa por recordar lo dicho por Marx en las secciones tercera, cuarta y quinta del tomo I de El capital referente a la producción de plusvalor como fuente de la ganancia de los capitalistas (Marx, 1975).

En el Prólogo a la edición alemana de "La situación de la clase obrera en Inglaterra", Engels muestra cómo el propio capital es capaz de metamorfosearse a sí mismo para lograr continuar con el proceso de explotación de plusvalor, incluso si esto le implica el frenar con la destrucción de las condiciones objetivas e, incluso, naturales de vida que el proletariado requiere para subsistir. Por ejemplo, ante "las repetidas epidemias de cólera, tifus, viruela y otras enfermedades" (Engels, 1976: 25) derivadas de la subordinación capitalista del proceso de trabajo y de las condiciones de vida del proletariado, se muetra que la clase burguesa no quedaba exenta de comenzar a sufrir las patologías que el propio capital había creado, por lo que la clase burguesa comenzó a propugnar para que se adoptasen medidas de cuidado y promoción de la salud.

Esta capacidad descrita por Engels respecto a la crisis de la salud que el capitalismo ha producido conforme subordina formal y realmente el proceso de producción de mercancías y la reproducción de la fuerza de trabajo, muestra cómo, al final, el propio capital ha tenido que "proceder al saneamiento de sus ciudades para no ser, él y su familia, víctimas de esas epidemias" (Engels, 1976: 25). Este argumento sirve para pensar, en el siglo XXI, la posibilidad de que el propio modo de producción capitalista deje de depredar y contaminar intensivamente las condiciones biofísicas de la naturaleza, en tanto que la crisis climática y ecológica han puesto en cuestión los propios canales de acumulación de capital. Cabe recalcar que esta adaptación del capitalismo para mejorar las condiciones sanitarias de la sociedad —e, incluso, las ambientales-, no se da por una simple dádiva o interés primigenio de la clase burguesa, sino que, precisamente, requiere que el movimiento del proletariado avance hacia esa dirección político revolucionaria que obligue al capital a dejar de devastar las condiciones de valor de uso de la población; además, la lucha del proletariado debe exigir que — tal y como lo advierte Engels en este Prólogo— la burguesía deje de "ocultar la miseria de la clase obrera" (Engels, 1976: 26).

Hacia el cierre argumental del Prólogo a la edición alemana de "La situación de la clase obrera en Inglaterra", podemos encontrar una interesante reflexión de Engels sobre las crisis económicas. En primer lugar, tomando en cuenta "la historia industrial de 1842 a 1868", establece que la duración de los ciclos de las crisis económicas "debe ser estimada en 10 años", pues "cada diez años, la marcha de la industria era violentamente interrumpida por una crisis general del comercio, seguida, tras un largo periodo de depresión crónica" (Engels, 1976: 29). Este argumento presentado por Engels se complementa con un interesante análisis sobre el desarrollo del capitalismo inglés posterior a la crisis económica de 1848 en Europa, presentando, cómo y en qué sentido, tras atravesar por una caída en la tasa de ganancia, el capital logró revertirle hasta el punto de desarrollarse como un modo de producción de hegemonía transcontinental.

Dicho argumento comienza con la presentación que Engels hace de la crisis inglesa de 1848, anunciando que, bajo dicha coyuntura, su resolución ocurriría solamente mediante una revolución violenta. Posteriormente, expone un análisis histórico materialista sobre el desarrollo de Inglaterra como país hegemónico del capitalismo europeo de fines del siglo XIX. Desde 1831 la burguesía industrial había logrado posicionarse como clase dominante hegemónica en Inglaterra, respecto al capital comercial, financiero y usurero, y en relación a la clase terrateniente, en la antesala de la revolución europea de 1848. 
Engels menciona que el desarrollo del capitalismo inglés avanzaba imparablemente hasta el punto de volver incuestionable su asunción como "el taller industrial del mundo" (Engels, 1976: 30), es decir, colocarle como país hegemónico que subordinara al resto de naciones europeas en "mercados para su producción industrial y fuentes de materias primas y de artículos alimenticios" (Engels, 1976: 30); es, precisamente, en este argumento de Engels que podemos reconocer que el colonialismo imperial no es ninguna fase especial de un capitalismo de alto desarrollo (Lenin, 2012 y Veraza, 1987), sino que, desde su medida geopolítica estrictamente continental (Veraza, 2013), dicha expresión del capitalismo de posicionar a una nación como el centro de una periferia "creciente de satélites productores" (30) de materias primas y fuerzas de trabajo que giraban en "torno al sol industrial" (30), formaba parte estructural de la dinámica con la cual el modo de producción capitalista subordinaba formal y realmente el proceso de trabajo a una escala geográfica cada vez mayor.

Esta reflexión sobre las crisis económicas y sobre el proceso de conversión de Inglaterra en el país hegemón en el contexto del capitalismo del siglo XIX, va acompañado por un balance sobre la correlativa emergencia de movimientos revolucionarios, mismos que desde la edición inglesa (1845) y norteamericana (1887) fueron pronosticados — muchas veces de manera certera (otras no) — por Engels a la luz del análisis histórico que realizó sobre el decurso del desarrollo histórico del capitalismo. Al respecto, Engels menciona que el recién aludido desarrollo del capitalismo y de las relaciones burguesas de explotación en Europa, se logró no sólo al papel de la burguesía como clase revolucionaria, sino que, también, a la habilidad política de ésta para aliarse con la clase proletaria, haciendo uso de la agenda política del proletariado para "establecer plenamente su dominio social y político" (Engels, 1976: 30).

La burguesía puede llegar a utilizar la propia lucha proletaria para sus propios intereses. Por ejemplo, Engels menciona que aunque la "Carta del Pueblo" — propuesta por el movimiento radical del Cartismo en Inglaterra - era un documento que pedía: 1) el voto universal y secreto para los obreros hombres; 2) un salario anual para aquellos obreros que ocupasen el puesto diputados en el Parlamento inglés; 3) la abolición de la condición de ser propietario para poder participar en la política parlamentaria; y 4) la elección anual de integrantes al Parlamento, bajo 5) condiciones equitativas de representatividad en el Parlamento, - a pesar de ello— terminó por convertirse "en el principal programa político" (Engels, 1976: 30) de la burguesía inglesa.

Esta subordinación de la agenda política del proletariado por el capital, se tradujo en un desarrollo sorprendente del capitalismo inglés, lo cual, obviamente, favorecía a la clase burguesa, sin embargo, Engels pregunta por cuál era la situación de la clase obrera ante este desarrollo del capitalismo (Engels, 1976). Como respuesta, Engels presenta argumentos para destacar que, tras la subordinación de la agenda política del proletariado inglés por la burguesía, en ocasiones "se producía un mejoramiento temporal" (32) en las condiciones de vida de la clase obrera, sin embargo, la propia dinámica de la acumulación de capital, terminaba por producir una nueva merma de las mismas por el engrosamiento de las filas del Ejercito Industrial de Reserva (Marx, 1975).

Este análisis presentado por Engels es redondeado por una explicación sobre la expansión geográfica del capitalismo y su potencialidad de convertirse — tal y como ocurrió efectivamente- en un modo de producción mundial. La explicación comienza argumentando que, si bien anteriormente la localización del complejo industrial capitalista estaba delimitada por la existencia de "las condiciones precisas" para que tal o cual empresa se instale, conforme las fuerzas productivas del capital se van desarrollando, dicha limitante objetivo territorial se ve superada conforme ocurre la mundialización del complejo productivo y energético del capitalismo en virtud de la configuración de una civilización material petrolera (Barreda, 2005). La segunda idea con la cual Engels argumenta este análisis sobre la mundialización del capitalismo, aborda cómo — de manera correlativa a la expansión territorial de la producción industrial - se va generalizando las zonas de comercio hasta el punto de plantearle la disyuntiva al propio capital de "crecer, extenderse o morir" (Engels, 1976: 36).

Engels concluye el Prólogo a la edición alemana de 1892 de "La situación de la clase obrera en Inglaterra", exponiendo cómo la propia lucha del proletariado ha pasado de las calles y fábricas hasta el propio terreno de la política institucional con el triunfo de obreros socialistas en las elecciones del Parlamento inglés. Este triunfo político del movimiento proletario, permitió que la clase obrera inglesa se constatara como una fuerza política decisiva (Engels, 1976).

En resumen, en este Prólogo se puede observar una mayor agudeza en la mirada crítico analítica de Engels respecto al desarrollo histórico y tendencial mundialización del capitalismo, misma que permite 
dar cuenta, por un lado, del perfeccionamiento de los instrumentos para la extracción de plusvalor a la clase proletaria por parte de la burguesía, llevándole incluyo — a esta última- a tener que adoptar o suplantar la propia agenta política de la clase obrera; demostrándose, con ello, la gran capacidad adaptativa del capitalismo para superar sus propias contradicciones. El argumento del Prólogo presentado por Engels para la edición alemana de "La situación de la clase obrera en Inglaterra" permite comprender cómo y en qué sentido dicha nación europea se convirtió en el país que hegemonizó el desarrollo internacional del capitalismo. Estos argumentos, sirven más que nunca para pensar nuestro tiempo en lo que refiere a la capacidad de reforma política del propio capitalismo en la coyuntura actual de crisis del neoliberalismo como política de acumulación y de la crisis climática y ecológica.

\section{A modo de conclusión: Un cuarto prologo a Situación de la clase obrera en Inglaterra (Notas para su redacción en referencia a la situación de la humanidad proletarizada en el siglo XXI)}

El libro "La situación de la clase obrera en Inglaterra" comienza con una dedicatoria que Friedrich Engels hace en 1845 a la clase trabajadora inglesa. En este texto titulado, precisamente, "A las clases obreras de Gran Bretaña", el autor comienza advirtiendo que en su libro no sólo se encontrarán una descripción de las condiciones de vida y pena en los que sobrevive el proletariado inglés, sino que también, se mostrará una mirada vital al momento de reconocer el principio de esperanza y de perspectiva histórica de transformación revolucionaria que representan los diversos intentos de la clase proletaria por constituirse como sujeto histórico, en aras de luchar en contra de los excesos cometido por el capital.

Esta dedicatoria permite observar el claro posicionamiento de clase que Engels hace a favor del proletariado, renunciando a los "banquetes, al vino y al champán" (Engels, 1976:2) que le aseguraba el haber nacido en el seno de una familia burguesa; además de permitir reconocer que, el objetivo principal que guarda "La situación de la clase obrera en Inglaterra", es el de hacer justicia al proletariado respecto a la serie de vejaciones cometidas por la burguesía que termina, según palabras de Engels, por tener intereses diametralmente opuestos e, incluso, antagónicos respecto a los de la clase trabajadora, en tanto que la clase capitalista "no persigue otro fin en realidad que la de enriquecerse" (3) por el trabajo del proletariado, por sacar provecho del "comercio indirecto de carne humana" (3) mediante la explotación y apropiación del plusvalor.

La crítica de Engels a la burguesía no sólo va en contra del "mercachifle inglés" (Engels, 1976: 3), sino que, también, se dirige en contra de quiénes asumen formalmente una posición cercana a las causas del proletariado pero que, en la práctica cotidiana, no prestan la atención mínima a los sufrimientos de la clase trabajadora a la hora de realizar informes burocráticos y con un talante administrativo que intentan dar cuenta de las condiciones de vida del proletariado pero sin denunciar las verdaderas condiciones de explotación y miseria en las que éste sector de la sociedad sobrevive.

La dedicatoria ofrecida por Engels a la clase trabajadora europea del siglo XIX, ha de ser percibida también por los oídos receptores de la humanidad proletarizada del siglo XXI. En la actualidad, el proceso de subsunción formal y real del proceso de trabajo por el capital ha alcanzado una medida geopolítica mundial (Veraza, 2013), por lo que el mercado mundial específicamente capitalista se encuentra realizado y sometiendo a una masa cada vez mayor de población a diversos mecanismos de explotación de plusvalor. En el siglo XXI, la ley general de la acumulación de capital se encuentra patentizada en la concentración de riqueza en un sector cada vez más reducido de la población, mientras que, por otro lado, se lleva a cabo una producción de miseria generalizada (Mateo, 2019); por tal motivo, resulta sumamente importante el análisis que Engels realiza sobre la relación que hay entre el desarrollo histórico del complejo maquinístico gran industrial capitalista y la conformación de la clase obrera, pues así se posibilita comprender el papel que hoy juega la clase proletaria como factor humano que ha quedado subordinado bajo el autómata planetario (Barreda, 2005) que se estructura como cuerpo tecnológico en los diversos procesos de producción de mercancías.

La concentración de la propiedad de los medios sociales de producción en manos de la burguesía forma parte estructural de nuestra historia contemporánea; la densificación demográfica en las megalópolis, la creación de corredores urbano-industriales, el hacinamiento de la población en unidades habitacionales carentes de servicios y construidas con materiales de pésima calidad, aparecen hoy día como titulares de las noticias que diariamente son publicadas a lo largo del mundo como expresión de una urbanización insostenible. 
Los temas presentados por Engels en "La situación de la clase obrera en Inglaterra" para ilustrar la degradación de las condiciones de vida del proletariado inglés y exponer las condiciones de posibilidad para la organización político revolucionaria de la clase oprimida por el capital, bien podrían ser empleados como una radiografía para dar cuenta de cómo es que (sobre)vive la clase proletaria a doscientos años de haber nacido el autor de dicho libro.

La mirada de continuidad presente en los tres Prólogos que Engels redactara para las ediciones inglesa, norteamericana y alemana de "La situación de la clase obrera en Inglaterra", se puede extender hasta la historia del capitalismo contemporáneo en pleno 2020; teniendo la particularidad y complejidad que en si mismo representa la realización y comprobación histórica de muchas de las predicciones realizadas por Engels tanto en 1845 como en 1887 y 1892; por ejemplo: la realización del mercado mundial capitalista o la hegemonía que durante el siglo XIX y principios del XX detentó efectivamente Inglaterra, misma que, posterior a la Segunda Guerra Mundial —concretamente después de 1945- le sería transferida a Estados Unidos; país que hasta el momento la detenta, a pesar de sus contradicciones y tensiones económicas y político-armamentistas con otras naciones capitalistas, China y Rusia incluidas.

Pero también, "La situación de la clase obrera en Inglaterra", escrita por Engels, es de alto valor para dar cuenta de las condiciones de posibilidad para la organización y lucha del proletariado mundial en contra del capital. A pesar de los descalabros que el movimiento proletario mundial ha sufrido, sobre todo, en correlación a la adopción de la política económica neoliberal, es importante reconocer que la humanidad proletarizada constituye una fuerza política, ya sea en potencia o en franca acción revolucionaria, para luchar y exigir al capital privado o social mejores condiciones de vida, tal y como sucediera en las manifestaciones sociales iniciadas en octubre de 2019 en Chile o con el movimiento de los "chalecos amarillos" en Francia; ambos acontecimientos daban cuenta, por un lado, de la crisis generalizada a nivel mundial del neoliberalismo pero, por otro lado, también mostraron la gran fuerza que representan los dominados modernos para echar adelante las ruedas de la historia en búsqueda de cambiar la correlación de fuerzas en la balanza de la lucha de clases en favor del proletariado.

Para hablarle al proletariado del siglo XXI, en un cuarto prólogo a "La situación de la clase obrera en Inglaterra", Engels tomaría en alta consideración, incluso, las importantes lecciones que pueda traer consigo la efervescencia que actualmente está teniendo el movimiento feminista y de la comunidad LGTBIQ (y aliados) por recobrar y conquistar sus derechos pisoteados, o no reconocidos hasta ahora, por unos y por otros. Engels pondría principal atención en papel de la clase obrera femenina como uno de los segmentos que actualmente representa el mayor sector al interior de la humanidad proletarizada en el siglo XXI, sobre todo, a partir de experiencias de movilización que en 2019 tuvieron las mujeres a nivel mundial para exigir un alto a la violencia desplegada por el capital.Para Engels sería central dar cuenta de la fortaleza que actualmente tiene el proletariado femenino respecto a la situación amordazada y fragmentada del proletariado masculino. Esta valoración de Engels para hablarle al proletariado mundializado en el siglo XXI, pasaría por reconocer la necesidad de reconocer al proletariado femenino y masculino bajo un mismo cuerpo, el cual — hasta el momento- se encuentra sin cabeza.

Ante esta clara vigencia de "La situación de la clase obrera en Inglaterra", sin embargo, cabe preguntar: ¿aunque estos puntos tematizados por Engels forman parte de la continuidad histórica del capitalismo a la luz de su propio desarrollo histórico, qué elementos pueden considerarse como novedosos y, por lo tanto, cruciales de comentarse en un cuarto Prólogo para la Edición de "La situación de la clase obrera en Inglaterra" a doscientos años de nacimiento de su autor?

Para comenzar con una idea general sobre el argumento central del contenido de dicho Prólogo, se tiene que comenzar por advertir que el capitalismo contemporáneo ha complicado el proceso de subsunción real del proceso de trabajo por el capital, hasta convertirle en un proceso de subsunción real del consumo bajo el capital (Veraza, 2009), en el cual predomina una tecnología capitalista nociva encargada de la producción de valores de uso que se caracterizan, principalmente, por ser de corte degradante y destructivo tanto de la emocionalidad como de la propia constitución fisiológica de la humanidad, además de producir una destrucción de las condiciones biofísico-químicas de la naturaleza como resultado de una acumulación originaria de capital residual y terminal (Veraza, 2007).

En este sentido, Engels —al redactar un cuarto prólogo a su libro- abordaría temas como los organismos genéticamente modificados, las armas de destrucción masivas, los virus creados en laboratorios como parte de una guerra bacteriológica, la fast food, la serie de enfermedades cada vez más complejas que aparecen para reactualizar el cuadro epidemiológico de la humanidad, serían apéndices que tendrían 
que agregarse en forma de notas para una edición de "La situación de la clase obrera en Inglaterra" que de cuenta del grado de degradación por el cual actualmente atraviesa la humanidad proletarizada tanto en lo que respecta a su psique y physis como al ambiente natural en el que se desenvuelve, mismo que se ha caracterizado por una crisis climática y ecológica de dimensiones y consecuencias planetarias. Además, se tiene que dar cuenta de la serie de desarrollos tecnológicos del capital como parte de los mecanismos de subsunción real del proceso de trabajo para la extracción de plusvalor, de allí que se tenga que dar cuenta, por ejemplo, del papel que juega actualmente la nanotecnología y la inteligencia artificial para la reproducción y desarrollo del capital.

Por todo lo anterior no sólo es de reconocerse la vigencia y actualidad teórica, política e histórica de "La situación de la clase obrera en Inglaterra", sino que, a partir de este reconocimiento explícito, se puede observar con claridad lo importante que representa hoy en día la mirada de Friedrich Engels para pensar, analizar y criticar científicamente al modo de producción capitalista mundialmente territorializado. A 200 años del nacimiento de Engels, vale la pena destacar el faro que representa su pensamiento como horizonte teórico para llevar a cabo una crítica global de la sociedad burguesa, mediante una praxis revolucionaria que posibilite la transformación y superación de las condiciones de miseria, enajenación y explotación que actualmente vive la humanidad por parte del capital; siendo, entonces, una tarea pendiente el rescatar y recurrir a la obra teórica de Engels para pensar cada una de las dimensiones macro y microsociales que acontecen en el capitalismo contemporánea, pues sólo así, se posibilitará que la marcha del proletariado por liberarse de sus cadenas logre avanzar hacia la conquista plena de la libertad de la humanidad.

\section{REFERENCIAS BIBLIOGRÁFICAS}

Asiner, J. (2018). Marxismo y Salud: acerca de "'La situación de la clase obrera en Inglaterra"". Hic. Rodus. Dossier: "Postas marxianas", (15), 83-86. https://publicaciones.sociales.uba.ar/index.php/hicrhodus/article/viewFile/3375/2787

Barreda, A. (2005) Geopolítica, recursos estratégicos y multinacionales. Jornadas Las Multinacionales Españolas en América Latina. Paz con Dignidad y Hegoa, Bilbao.

Dennehy, A. (1996). The condition of the working class in England: 150 years on. In Engels Today (pp. 95-127). Palgrave Macmillan, London. https://cutt.ly/ntl8xWT

Engels, F. (1976). "La situación de la clase obrera en Inglaterra". Madrid: Akal.

Fanon, F. (2009). Piel negra, máscaras blancas (Vol. 55). Ediciones Akal. https://cutt.ly/7tlPtk

Grüner, E. (2006). Lecturas culpables. Marx(ismos) y la práxis del conocimiento. CLACSO. https://cutt.ly/beVzpCq

Hobsbawm, E. (1977). Del feudalismo al capitalismo. Hilton, R. Transición del feudalismo al capitalismo. Barcelona: Crítica, 201-208. https://cutt.ly/mtlOlzG

Kohan, N. (2007). Introducción al pensamiento socialista. El socialismo como ética revolucionaria y teoría de la rebelión. Argentina: Ocean Sur. https://cutt.ly/wtllOng

Lefebvre, H. (1991). The production of space. Blackwell: Oxford.

Lefebvre, H. (2003). The urban revolution. U of Minnesota Press: Minnesota.

Lenin, V. I. (1895). Federico Engels. Grijalbo, Barcelona. https://cutt.ly/JtIIM4a

Lenin, V. I. (2012). Imperialismo: la fase superior del capitalismo. Taurus. https://cutt.ly/MtIPKZn

Luckács, G. (1975). Historia y conciencia de clase (1923). Barcelona, Grijalbo.

Mateo Tomé, J. P. (2019). Capital, trabajo y la ley general de la acumulación. Sociología Histórica, (9), 507-534. Recuperado a partir de https://revistas.um.es/sh/article/view/299281

Marx, K. (1975). El Capital. Crítica de la Economía Política. Tomo I . D.F., México: Siglo XXI. https://cutt.ly/GtlOL5U

Marx, K. (1987). El capital. Libro I, capítulo VI (inédito): Resultados inmediatos del proceso de producción (Vol. 1). Siglo XXI. https:// cutt.ly/ftll8Eu

Marx, K. (1990). Contribución a la crítica de la economía política. Siglo XXI. Barcelona.

Marx, K., \& Engels, F. (1974). Manifiesto del Partido Comunista, obras escogidas. Editorial Progreso, Moscú.

Moreno, I., \& Pereira, G. (2018). A 150 años de la primera edición de El capital. 1867-2017. https://cutt.ly/GtlO1IJ

Patterson, T. (2014). Karl Marx, Anthropologist. England. Lectulandia

Roggerone, (2013). Un movimiento de la derrota. Apuntes sobre el joven Engels y el hegelianismo de izquierda. VII Jornadas de Jóvenes Investigadores. Instituto de Investigaciones Gino Germani, Facultad de Ciencias Sociales, Universidad de Buenos Aires, Buenos Aires. https://www.aacademica.org/000-076/240.pdf

Valero, P. (2010). Esbozo para una crítica del racismo colonia: Un diálogo entre Fanon, Marx y Engels. En: Vargas, M. [coord.](2010). Guerrero de Silicio: Ecos a la obra de Franz Fanon. México. Centro de Investigaciones sobre América Latina y el Caribe, UNAM. https://cutt.ly/rrBQdFv 
Santella, A. (2018). Crítica del libro. Marx discípulo de Engels. Una nueva lectura de la génesis del marxismo. Revista de Estudios Marítimos y Sociales, 1(12), 215-218. https://cutt.ly/4tIPcco

Scarpacci, M. (2016). URVIO. Revista Latinoamericana de Estudios de Seguridad, (19), 7-15. https://cutt.ly/Ptc5XOv

Veraza, J. (1987). Para la crítica a las teórías del imperialismo. Cdmx: Editorial Itaca

Veraza, J. (2004). El siglo de la hegemonía mundial de Estados Unidos: Guía para comprender la historia del Siglo XX, Muy útil para el Siglo XXI. Tláhuac: Editorial Itaca. https://cutt.ly/YtlPxQj

Veraza, J. (2007). Economía y política del agua. El agua que te vendo primero te la robé. CDMx: Editorial Itaca.

Veraza, J. (2009). Subsunción real del consumo bajo el capital. Dominación fisiológica y psicológica en la sociedad contemporánea. D.F., CDMx, México: Itaca.

Veraza, J. (2011). Karl Marx y la técnica desde la perspectiva de la vida. Para una teoría marxista de las fuerzas productivas. CDMx, México: Itaca.

Veraza, J. (2013). El sentido de la historia y las medidas geopolíticas del capital: crítica a intérpretes del Manifiesto del Partido Comunista. La Paz, Bolivia: Vicepresidencia del Estado Plurinacional de Bolivia.

How to cite this article: Luna-Nemecio, J. (2020). Comentario a los prólogos de "La situación de la clase obrera en Inglaterra", de Friedrich Engels a 200 años de su nacimiento. Religación. Revista De Ciencias Sociales Y Humanidades, 5(23)، 16-30. Recuperado a partir de http://revista.religacion.com/index.php/religacion/article/view/592

Submitted: 04 January 2020 Accepted: 19 March 2020 Published: 31 March 2020

Religación. Revistais de Ciencias Sociales y Humanidades is a peer-reviewed open access journal published by CICSH-AL Centro de Investigaciones en Ciencias Sociales y Humanidades desde América Latina |Religación| 